\title{
Factors contributing to quality of life in COPD patients in South Korea
}

\author{
This article was published in the following Dove Press journal: \\ International Journal of COPD \\ 13 January 2016 \\ Number of times this article has been viewed
}

\author{
Hye-Young Kwon ${ }^{1,2}$ \\ Eugene $\mathrm{Kim}^{2}$ \\ 'Department of Global Health \\ and Population, Harvard School of \\ Public Health, Boston, MA, USA; \\ ${ }^{2}$ Institute of Health and Environment, \\ Graduate School of Public Health, \\ Seoul National University, Seoul, \\ South Korea
}

Objectives: Chronic obstructive pulmonary disease (COPD) is a chronic lung disease, and the burden of COPD is expected to increase in the rapidly aging nation of South Korea. This study aims to examine the factors contributing to health-related quality of life (HRQOL) in COPD patients.

Patients and methods: This study was based on 6-year-data obtained from the Korean National Health and Nutrition Examination Survey 2007-2012. COPD was diagnosed in 2,734 survey participants and the severity was graded according to the criteria set by the Global Initiative for Chronic Obstructive Lung Disease. The EuroQol-5D (EQ-5D) index was used to assess the quality of life.

Results: The EQ-5D index scores for COPD patients and the general population were $0.915 \pm 0.003$ and $0.943 \pm 0.001$, respectively. Males, younger people, and patients with higher education attainment and income levels had a higher utility score. In addition, the adjusted EQ-5D index scores for severity level IV significantly decreased by 0.100 ( $P=0.041)$, compared to the severity group I scores. No significant differences were found in stage II and III patients. Comorbidities (excluding cancer and hypertension) appeared to negatively influence HRQOL among COPD patients. In particular, depression (EQ-5D index score $=-0.089, P=0.0003$ ) and osteoporosis (EQ-5D index score $=-0.062, P=0.0039$ ) had a significant influence, while smoking status did not appear to influence patient HRQOL.

Conclusion: In this study, we found that the higher the severity of COPD, the lower the quality of life. In particular, patients with depression and osteoporosis had a relatively low utility score. Therefore, these comorbidities should be carefully monitored in order to improve quality of life.

Keywords: COPD, HRQOL, EQ5D, KNHANES, South Korea

\section{Introduction}

Chronic obstructive pulmonary disease (COPD) is a common preventable and treatable disease. COPD is characterized by persistent airflow limitation that is usually progressive and associated with an enhanced chronic inflammatory response in the airway and the lung, due to noxious particles or gases. ${ }^{1}$ According to the 2008 Korean National Health and Nutrition Examination Survey (KNHANES), COPD affects 10\% of the global population and $13.4 \%$ of South Korean individuals aged 40 years or older (males: $19.4 \%$; females: $7.9 \%)^{2}$

In contrast to the general trend demonstrating gradually decreasing mortality rates for other chronic diseases, mortality rates associated with COPD are gradually increasing. ${ }^{3}$ In South Korea, COPD was the seventh leading cause of death in 2013. The prevalence of COPD increases with age, and it was the fifth leading cause of death in older age-groups ( $\geq 80$ years). ${ }^{4}$

Because early detection of COPD is difficult, diagnosis and treatment are often delayed. In the study conducted by Yoo et al, ${ }^{5}$ patients were diagnosed with COPD
Graduate School of Public Health, 221

Bldg, \#40 I Seoul National University,

Seoul, I5I-742 South Korea

Tel +8228802724

Fax +82 27629105

Email dainty09@naver.com 
according to the results obtained from pulmonary function tests conducted as part of the KNHANES. Among these, only $2.4 \%$ of COPD patients reported a diagnosis of COPD, and only $2.1 \%$ had received appropriate treatment. This suggests that timely COPD diagnosis and treatment in South Korea is almost nonexistent. ${ }^{5}$

The burden of COPD is expected to increase in the aging South Korean population. This is because the smoking rates in South Korea are higher compared to other countries, ${ }^{6}$ and mortality rates associated with COPD rapidly increase after the age of 50 years, while also being higher in males than in females. ${ }^{7}$ Additionally, the increase in the number of COPD patients is expected to rapidly increase as a result of exacerbating factors such as aging-related diseases, smoking, and air pollution. As such, there is an urgent need to establish policies and strategies for the efficient management of COPD, and more research is required to achieve this.

Health-related quality of life (HRQOL) has been receiving greater attention as a result of increasing income levels and life expectancy, which has been brought about by advances in medical technology. However, due to the rapidly rising number of patients with chronic diseases in an aging society, the focus has shifted from mere survival to a better quality of life. This is consistent with the increasing interest in an alternative index to measure quality of life. An alternative index would go beyond the scope of an economic index, such as that of gross domestic product which has been used as a key index to measure a nation's economic development, as economic growth itself does not ensure wellbeing or improve the quality of life of the general population. ${ }^{8}$

HRQOL refers to an individual's satisfaction or happiness with aspects of life, as they affect or are affected by their health. ${ }^{9-11}$ HRQOL is a multidimensional concept that includes aspects related to physical, mental, emotional, and social functioning. It extends beyond direct measures of population health, life expectancy, and causes of death, and focuses on the impact of health on quality of life. ${ }^{12-13}$ Generalized HRQOL instruments (eg, the EuroQol-5D [EQ-5D]), are designed to be applicable across all diseases or conditions, different medical interventions, and a wide range of populations. The EQ-5D includes questions in five domains: mobility, self-care, daily activities, pain, and mood. ${ }^{14}$

In South Korea, even though HRQOL, as associated with various other diseases, has been studied, ${ }^{15-17} \mathrm{HRQOL}$ in the context of COPD has not been researched. Therefore, given the increasing prevalence and burden of COPD, exploring the HRQOL among patients with COPD will be informative for health professionals and decision makers. In this study, we examine HRQOL in South Korean patients with COPD and the factors affecting their quality of life based on the KNHANES data containing the EQ-5D scores as HRQOL.

\section{Patients and methods}

The KNHANES is a large-scale annual nationwide survey conducted by the Ministry of Health and Welfare and the Korea Center for Disease Control. Its purpose is to generate statistical data on the general health and nutrition status of South Koreans, and to identify population groups that should be prioritized when considering health policies. A stratified, multistage probability sampling design, taking into account the location and residence-type, was used in the KNHANES in order to establish nationwide representativeness. ${ }^{18}$

This study was based on 6-year-data obtained from the KNHANES 2007-2012. ${ }^{18-19}$ Thus, cross-sectional surveys conducted over a period of 6 years were pooled for analysis. Using the data for the forced expiratory volume in 1 second $\left(\mathrm{FEV}_{1}\right)$ and the forced vital capacity (FVC) of adults ( $\geq 19$ years), COPD patients were identified from 50,405 participants of the KNHANES 2007-2012, and they were classified according to the criteria of the Global Initiative for Chronic Obstructive Lung Disease (GOLD) (ie, individuals with $\mathrm{FEV}_{1}$ /forced vital capacity $<0.7$ were considered as having COPD). ${ }^{1}$ In total, 2,734 patients who were defined as COPD patients were included in this study. Because the $\mathrm{FEV}_{1}$ percent is the predicted outcome value in lung disease, ${ }^{20}$ COPD patients were classified according to the predicted $\mathrm{FEV}_{1}$ values into the following four categories as per the GOLD criteria: mild ( $\geq 80 \%)$, moderate $(50 \%-79 \%)$, severe $(30 \%-49 \%)$, and very severe $(<30 \%)$.

The average score of the EQ-5D index was calculated to assess the quality of life of COPD patients by using the South Korean specific tariff that is based on the time-trade-off method. ${ }^{21-22}$ In order to identify factors contributing toward quality of life, a multivariate regression was performed using PROC SURVEYMEANS and PROC SURVEYREG. Demographic variables (eg, sex and age), socioeconomic status variables, including education and income, smoking status, severity of COPD, and comorbidities (eg, hypertension, diabetes, depressive disorder, cancer, and osteoporosis) were used as independent variables. Osteoporosis and depression were especially considered as comorbidities, as it has been found that these are common in COPD and can adversely affect quality of life. ${ }^{23-27}$ SAS version 9.4 (SAS Institute Inc., Cary, NC, USA) was used for statistical analysis. The institutional review board (IRB) of the KCDC reviewed and approved the KNHANES survey annually 
and the IRB approval numbers were 2007-02CON-04-P, 2008-04EXP-01-C, 2009-01CON-03-2C, 2010-02CON21-C, 2011-02CON-06-C, and 2012-01EXP-01-2C. All of the data were downloaded from the official website of the KNHANES (http://knhan-es.cdc.go.kr/). These data are open to the public after completing a designated registration process for access.

\section{Results}

\section{Population characteristics}

Table 1 shows the basic characteristics for the general population and COPD patients in South Korea. The weighted general population was $28,820,557$, of which $51.4 \%$ consisted of males with an average age of 30.57 years. Individuals over the age of 40 years accounted for $25.28 \%$ of the population. With regards to socioeconomic factors, income levels were fairly evenly distributed, with the elementary or lower levels of education showing the highest distribution (39.78\%), and $64.03 \%$ were homeowners. In terms of health-related factors, $95.94 \%$ of patients had health insurance and $24.29 \%$ were current smokers. The overall quality of life was EQ-5D index 0.9425 (standard deviation \pm 0.001 ).

Table I Basic characteristics of the study population

\begin{tabular}{ll}
\hline Characteristics & COPD patients $\mathbf{( N = 2 , 2 5 4 , 5 5 6 )}$ \\
\hline Sex & \\
Male, \% & $72.36(0.12)$ \\
Age (yrs), mean & $60.37(0.34)$ \\
Age-groups (yrs), \% & \\
$\quad<40$ & $5.67(0.61)$ \\
$40-49$ & $13.08(0.94)$ \\
$50-59$ & $25.96(1.17)$ \\
$60-69$ & $28.93(1.02)$ \\
$70-79$ & $22.78(0.90)$ \\
$80+$ & $3.58(0.41)$ \\
Income, \% & \\
Low & $30.25(1.14)$ \\
Middle & $26.69(1.15)$ \\
Upper middle & $22.99(1.12)$ \\
High & $20.07(1.09)$ \\
Education level, \% & \\
$\quad<$ Primary school & $41.83(1.27)$ \\
Middle school & $17.76(0.96)$ \\
High school & $26.47(1.17)$ \\
College + & $13.95(0.84)$ \\
Housing, \% & \\
Owners & $73.54(1.23)$ \\
Insurance type, \% & \\
NHI & $95.61(0.52)$ \\
Medical aid & $4.39(0.52)$ \\
Smoking, \% & $51.08(1.23)$ \\
Current & $19.62(0.92)$ \\
Ex-smoker & $29.30(1.15)$ \\
Nonsmoker & $48.92(1.29)$ \\
Flu vaccination, \% &
\end{tabular}

Note: Standard errors in parentheses.

Abbreviations: NHI, National Health Insurance; yrs, years.
The COPD prevalence was $7.82 \%$. Among the COPD patients, $72.36 \%$ were male with an average age of 60.37 $( \pm 0.34)$ years. A higher rate of COPD was observed in individuals over the age of 50 years. In terms of smoking, which is the most significant contributing factor for COPD, 51.08\% of the survey participants were current smokers, $19.62 \%$ were ex-smokers, and the rest were nonsmokers. These figures indicate a higher rate of smokers among COPD patients compared to the general population. Influenza immunization, which is recommended as a preventive measure against COPD, ${ }^{1}$ was more prevalent among COPD patients than in the general population ( $34.78 \%$ vs $48.92 \%)$. Patients with COPD were highly represented in the bottom quartile of the income level. Quality of life was $0.915( \pm 0.003)$, which was lower than that of the general population.

Patient characteristics according to COPD severity are shown in Table 2. Mild (41.28\%) and moderate (52.45\%) severity levels accounted for the majority of COPD cases, with the severe and very severe stages accounting for $5.69 \%$ and $0.58 \%$ of cases, respectively. COPD prevalence was significantly higher in males than in females $(P=0.00388)$, but there were no significant differences in the severity between age-groups. Income was significantly influenced by the severity of COPD ( $P=0.0037)$, but the education level and home ownership status did not show statistically significant differences. Current smokers accounted for the highest percentage in all severity levels, and the influenza immunization rate increased with increasing COPD severity $(P=0.0028)$.

Hypertension and diabetes were the most frequent comorbidities, but did not exhibit severity-dependent differences. Other comorbidities, such as cancer, cardiovascular diseases, and depression, with the exception of osteoporosis $(P=0.0337)$, did not exhibit severity-dependent differences either.

Only $2.46 \%$ of the COPD patients identified by the GOLD criteria answered that they had been diagnosed with the condition, which clearly indicates that for the most part, COPD diagnosis and treatment is not conducted in a timely manner. As a matter of fact, the diagnosis rate is $1.16 \%$ in the severe and very severe COPD stages, and $1.29 \%$ in the mild-to-moderate stages, suggesting that interventions for early diagnosis and treatment are desperately needed.

\section{HRQOL among COPD patients}

HRQOL among COPD patients varied depending on disease severity and comorbidities. As Figure 1 shows, the utility score for the general South Korean population was $0.943 \pm 0.001$, while COPD in general scored $0.915 \pm 0.003$, which is a significant difference compared to non-COPD 
Table 2 Patient characteristics according to COPD severity $(\mathrm{N}=2,254,556)$

\begin{tabular}{|c|c|c|c|c|c|c|}
\hline \multirow[t]{2}{*}{ Characteristics } & \multicolumn{4}{|c|}{ GOLD criteria } & \multirow[t]{2}{*}{ Total (SE) } & \multirow[t]{2}{*}{$P$-value } \\
\hline & $\mathbf{I}$ & II & III & IV & & \\
\hline \multicolumn{7}{|l|}{ Sex } \\
\hline Male, \% & $31.40(1.09)$ & $36.58(1.16)$ & $3.97(0.44)$ & $0.4 I(0.13)$ & $72.36(1.12)$ & $P=0.0388$ \\
\hline Female, \% & $9.88(0.66)$ & I5.87 (0.90) & $\mathrm{I} .72(0.32)$ & $0.17(0.11)$ & $27.64(1.12)$ & \\
\hline Total & $41.28(1.12)$ & $52.45(1.14)$ & $5.69(0.54)$ & $0.58(0.17)$ & & \\
\hline Age (yrs), mean & $62.47(0.47)$ & $58.78(0.45)$ & $59.65(1.72)$ & $62.53(3.08)$ & $60.37(0.34)$ & NS \\
\hline \multicolumn{7}{|l|}{ Insurance type, \% } \\
\hline $\mathrm{NHI}$ & $39.87(1.14)$ & $50.14(1.16)$ & $5.03(0.5 \mathrm{I})$ & $0.56(0.17)$ & $95.61(0.52)$ & $P=0.0002$ \\
\hline Medical aid & $1.52(0.30)$ & $2.13(0.34)$ & $0.7 \mid(0.23)$ & $0.03(0.02)$ & $4.39(0.52)$ & \\
\hline \multicolumn{7}{|l|}{ Housing, \% } \\
\hline Owners & $30.91(1.05)$ & $38.38(1.14)$ & $3.87(0.43)$ & $0.39(0.14)$ & $73.54(1.23)$ & $P=0.48 \mid 4$ \\
\hline \multicolumn{7}{|c|}{ Income level (household), \% } \\
\hline Low & I3.44 (0.80) & $14.29(0.84)$ & $2.10(0.34)$ & $0.4 I(0.13)$ & $30.25(1.14)$ & \\
\hline Middle & $10.02(0.73)$ & $|4.8|(0.86)$ & $\mathrm{I} .78(0.30)$ & $0.07(0.06)$ & $26.69(1.15)$ & \\
\hline Upper middle & $8.73(0.75)$ & $13.13(0.85)$ & $1.12(0.30)$ & $0.01(0.01)$ & $22.99(1.12)$ & \\
\hline High & $9.24(0.72)$ & $10.01(0.82)$ & $0.72(0.23)$ & $0.10(0.10)$ & $20.07(1.09)$ & \\
\hline \multicolumn{7}{|l|}{ Education level, \% } \\
\hline$<$ Primary school & $16.88(0.83)$ & $21.37(0.98)$ & $3.18(0.42)$ & $0.40(0.13)$ & $41.83(1.27)$ & $P=0.0037$ \\
\hline Middle school & $7.4 \mathrm{I}(0.63)$ & $9.34(0.74)$ & $0.89(0.20)$ & $0.1 I(0.10)$ & $17.76(0.96)$ & \\
\hline High school & $11.56(0.82)$ & $13.62(0.90)$ & $1.26(0.33)$ & $0.03(0.03)$ & $26.47(1.17)$ & \\
\hline College + & $5.55(0.55)$ & $7.95(0.66)$ & $0.40(0.13)$ & $0.05(0.05)$ & $13.95(0.84)$ & \\
\hline \multicolumn{7}{|l|}{ Smoking, \% } \\
\hline Current & $21.35(0.98)$ & $26.20(1.05)$ & $3.20(0.4 \mathrm{I})$ & $0.33(0.12)$ & $51.08(1.23)$ & $P=0.0004$ \\
\hline Ex-smoker & $9.90(0.72)$ & $8.84(0.66)$ & $0.83(0.22)$ & $0.04(0.03)$ & $19.62(0.92)$ & \\
\hline Nonsmoker & $10.16(0.68)$ & $17.23(0.90)$ & $1.69(0.34)$ & $0.22(0.13)$ & $29.30(1.15)$ & \\
\hline Flu vaccination, $\%$ & $20.82(0.94)$ & $24.09(0.98)$ & $3.57(0.42)$ & $0.44(0.15)$ & $48.92(1.29)$ & $P=0.0028$ \\
\hline Diagnosed as COPD, \% & $0.13(0.05)$ & $1.16(0.23)$ & $0.97(0.21)$ & $0.19(0.09)$ & $2.46(0.32)$ & $P<0.0001$ \\
\hline \multicolumn{7}{|l|}{ Comorbidities, \% } \\
\hline Hypertension & $13.27(0.76)$ & $|6.4|(0.86)$ & $1.78(0.30)$ & $0.33(0.14)$ & $31.79(1.06)$ & $P=0.3565$ \\
\hline Diabetes mellitus & $4.35(0.42)$ & $7.16(0.58)$ & $0.7 I(0.22)$ & $0.01(0.01)$ & $12.23(0.70)$ & $P=0.0990$ \\
\hline Cancer & $0.69(0.15)$ & $0.84(0.22)$ & $0.02(0.02)$ & - & $1.55(0.28)$ & $\mathrm{N} / \mathrm{A}$ \\
\hline $\mathrm{CV}$ events & $2.02(0.31)$ & $3.13(0.4 I)$ & $0.4 I(0.12)$ & - & $5.57(0.54)$ & N/A \\
\hline Osteoporosis & $0.77(0.17)$ & $\mathrm{I} .75(0.27)$ & $0.05(0.04)$ & $0.02(0.02)$ & $2.59(0.32)$ & $P=0.0337$ \\
\hline Depressive disorder & $\mathrm{I} .42(0.27)$ & $1.38(0.26)$ & $0.32(0.15)$ & $0.02(0.02)$ & $3.15(0.39)$ & $P=0.2740$ \\
\hline
\end{tabular}

Note: Standard errors in parentheses.

Abbreviations: GOLD, Global Initiative for Chronic Obstructive Lung Disease; yrs, years; N/A, not applicable; SE, standard error; NHI, National Health Insurance; CV, cardiovascular; NS, not significant.

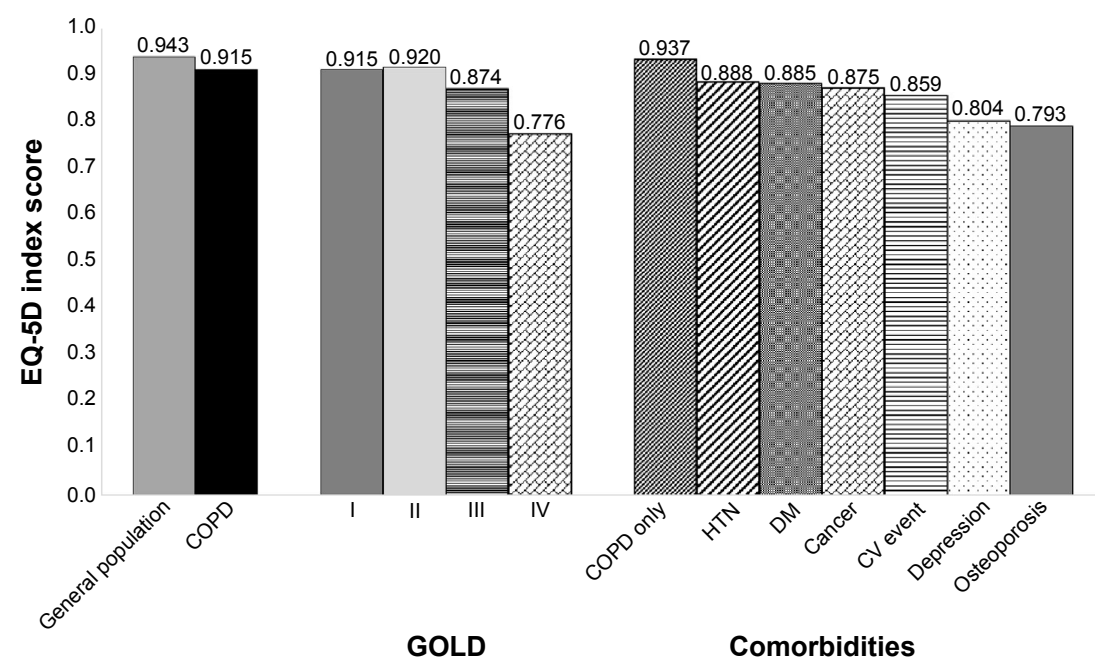

Figure I EQ-5D index among patients with COPD.

Abbreviations: EQ-5D, EuroQol-5D; GOLD, Global Initiative for Chronic Obstructive Lung Disease; HTN, hypertension; DM, diabetes melitus; CV, cardiovascular. 
patients $(P<0.0001)$. The utility score did not differ much between the mild $(0.915 \pm 0.005)$ and moderate $(0.920 \pm 0.004)$ severity levels, but there was a significant decrease in the utility scores for the severe $(0.874 \pm 0.020, P=0.0447)$ and very severe $(0.776 \pm 0.056, P=0.0133)$ levels.

Patients with comorbidities had lower utility scores than COPD-only patients $(0.937 \pm 0.004, P<0.0001)$. The HRQOL scores of COPD patients according to comorbidities were as follows: hypertension $(0.888 \pm 0.006)$; diabetes (0.885 \pm 0.010$)$; cancer $(0.875 \pm 0.022)$; cardiovascular event $(0.859 \pm 0.014)$; depression $(0.804 \pm 0.024)$; and osteoporosis $(0.793 \pm 0.021)$. The HRQOL scores of COPD patients with hypertension $(P<0.0001)$, diabetes $(P=0.0009)$, cardiovascular diseases $(P<0.0001)$, depression $(P<0.0001)$, and osteoporosis $(P<0.0001)$ were significantly different from those of their counterparts without comorbidities. COPD patients with osteoporosis had the lowest utility scores.

COPD patients who had depression or osteoporosis as comorbidities had HRQOL scores that were relatively lower, indicating that more attention should be given to patients with comorbidities.

\section{Factors affecting the HRQOL of COPD patients}

Table 3 outlines the results of a multivariate regression to investigate the factors contributing to the HRQOL of COPD patients. In Table 3, all factors, with the exception of smoking, had a significant influence on the HRQOL in COPD patients. Compared to females, the average utility score for males was higher by $0.034(P=0.004)$. Utility scores decreased by 0.001 for each higher age-group $(P=0.001)$. The group with the lowest education level had significantly lower utility scores $(P<0.0001)$, and the lowest HRQOL was exhibited by patients with the lowest income level $(P<0.0001)$.

COPD patients who had already been diagnosed with COPD had lower utility scores of 0.039 ( $P=0.053)$, compared to the undiagnosed patients' scores. The utility scores of patients with a very severe stage of COPD were lower by 0.100 ( $P=0.041$ ), compared to patients with level I severity. No significant differences were found in patients with other grades of severity.

Asides from cancer and hypertension, all comorbidities were found to exert negative influences on the HRQOL of COPD patients. Influences exerted by depression $(-0.089$, $P=0.0003)$ and osteoporosis $(-0.062, P=0.0039)$ were found to be highly significant. Patients with concomitant cancer or hypertension did not show any significant changes in HRQOL
Table 3 Results of multivariate regression to predict factors associated with HRQOL in patients with COPD

\begin{tabular}{|c|c|c|c|}
\hline Dependent variables & Estimates & SE & $t$-value \\
\hline Intercept & $0.910 * *$ & 0.052 & 17.650 \\
\hline \multicolumn{4}{|l|}{ Sex } \\
\hline Male & $0.034 * *$ & 0.012 & 2.870 \\
\hline Female (ref) & - & - & - \\
\hline Age & $-0.00 I^{* *}$ & 0.000 & -3.280 \\
\hline \multicolumn{4}{|l|}{ Education } \\
\hline$<$ Primary school & $-0.049 * *$ & 0.009 & -5.350 \\
\hline Middle school & -0.009 & 0.009 & -0.990 \\
\hline High school & -0.002 & 0.008 & -0.250 \\
\hline College + (ref) & - & - & - \\
\hline \multicolumn{4}{|l|}{ Income level } \\
\hline Low & $-0.038^{* *}$ & 0.009 & -4.320 \\
\hline Middle & -0.008 & 0.008 & -1.010 \\
\hline Upper middle & 0.003 & 0.006 & 0.510 \\
\hline High (ref) & - & - & - \\
\hline Diagnosed as COPD & -0.039 & 0.020 & -1.940 \\
\hline \multicolumn{4}{|l|}{ Severity } \\
\hline ॥ & 0.003 & 0.006 & 0.560 \\
\hline III & -0.024 & 0.019 & -1.300 \\
\hline IV & $-0.100 * *$ & -0.049 & -2.050 \\
\hline I (ref) & - & - & - \\
\hline \multicolumn{4}{|l|}{ Comorbidities } \\
\hline Hypertension & -0.010 & 0.007 & -1.420 \\
\hline Diabetes & $-0.020 *$ & 0.010 & -2.060 \\
\hline Depression & $-0.089 * *$ & 0.025 & -3.630 \\
\hline Osteoporosis & $-0.062 * *$ & 0.022 & -2.900 \\
\hline $\begin{array}{l}\text { Cardiovascular } \\
\text { events }\end{array}$ & $-0.037^{* *}$ & 0.014 & -2.740 \\
\hline Cancer & 0.005 & 0.015 & 0.290 \\
\hline \multicolumn{4}{|l|}{ Smoking } \\
\hline Current & -0.011 & 0.011 & -0.960 \\
\hline Ex-smoker & 0.004 & 0.012 & 0.290 \\
\hline Nonsmoker (ref) & - & - & - \\
\hline $\mathrm{R}^{2}$ & 0.1775 & & \\
\hline
\end{tabular}

Note: $* P<0.05, * * P<0.001$

Abbreviations: HRQOL, health-related quality of life; SE, standard error; ref, reference.

compared to other patients. Smoking status did not exert any significant influence on the HRQOL either.

\section{Discussion}

In this study, EQ-5D index scores were used to measure the quality of life, ie, HRQOL, in COPD patients, and to identify the factors influencing HRQOL. The study's findings verified that the higher the COPD severity level, the lower the HRQOL. Additionally, the study verified that demographic factors, such as sex and age, socioeconomic factors, and comorbidities, also influenced HRQOL. These findings are consistent with those of previous studies, which found that patients' demographic and socioeconomic characteristics significantly influenced HRQOL..$^{28}$ According to previous 
studies, male COPD patients have a higher HRQOL than their female counterparts, and age is negatively associated with HRQOL, while education level and income level are positively associated. When comparing these results with related foreign literature, it is revealed that HRQOL is generally higher in South Korean COPD patients than in their British counterparts; however, both show decreasing HRQOL with increasing severity of COPD. ${ }^{29-32}$

This study has limitations. In this study, COPD diagnosis was based on pulmonary function test data from the KNHANES. Since the KNHANES has not conducted bronchodilator reversibility testing to diagnose COPD, asthmatic patients can be included in the study population. Thus, the results may be biased because of the pulmonary function test was not mandatory and has been conducted voluntarily. Considering the low level of awareness among patients and the low COPD diagnosis rate, the test might have been done selectively which may lead bias on the results. Because the pulmonary test was not mandatory, survey participation from patients with severe COPD may have been low, and even among the participants, some may have refused to take the pulmonary function test. It is, therefore, possible that the number of cases was overestimated. Furthermore, patients with severe diseases such as cancer, and individuals who had experienced cardiovascular events, may have refused to take part in the survey. Nevertheless, the implications of the study's findings are significant, given that they were derived from the KNHANES data, the strength of which lies in a sample design that ensures nationwide representativeness, and thus, enables the measurement of the nation's HRQOL by disease type.

This study found that only $2.46 \%$ of COPD patients had been officially diagnosed. This confirmed the need for interventional measures to improve the awareness of COPD among patients as part of chronic disease management, as well as to improve the COPD diagnosis rate among physicians. Smoking is a major risk factor for COPD, and therefore education and lifestyle changes are required as preventive measures. The current study also confirmed that the HRQOL of patients with high-severity COPD and osteoporosis or depression as comorbidities was particularly low, indicating the need for efforts to improve their quality of life.

The number of patients with COPD is expected to increase as a result of an aging society, environmental changes, and air pollution. Considering the extremely low awareness of this disease at present, the low early detection rate, and the lack of preventive measures, this study is expected to have implications in establishing policies that improve the health status and quality of life of patients with COPD.

\section{Disclosure}

There were no external funding sources for this study. The authors declare no conflicts of interest in this work.

\section{References}

1. Global Initiative for Chronic Obstructive Lung Disease (GOLD). Workshop report: Global strategy for the diagnosis, management, and prevention of COPD; 2001. Available from: www.goldcopd.com. Accessed December 17, 2014.

2. Jung GS, Yoo KH, Park YB, et al. The strategies for prevention and control of COPD. Seoul; Korea Centers for Disease Control and Korea Society of Tuberculosis and Respiratory Diseases; 2014. Available from: http://www.lungkorea.org/thesis/file/chronic_obstructive_ pulmonary_disease_2014.pdf

3. National Heart, Lung, and Blood Institute (NHLBI). NHLBI Fact Book, Fiscal Year 2012; 2012. Available from: http://www.nhlbi.nih.gov/about/ documents/factbook/2012/chapter4\#4_3. Accessed March 23, 2014.

4. Statistics Korea [homepage on the internet]. Statistics on causes of mortality; 2013. Available from: http://kostat.go.kr. Accessed May 22, 2015.

5. Yoo KH, Kim YS, Sheen SS, et al. Prevalence of chronic obstructive pulmonary disease in Korea: the fourth Korean National Health and Nutrition Examination Survey 2008. Respirology. 2011;16(4): 659-665.

6. Ministry of Health and Welfare, 2013 OECD Health Data in Korean, MOHW and Korean Institute for Health And Social Affairs, Seoul; 2013.

7. World Health Organization (WHO) [homepage on the internet]. Global Burden of Disease 2013. Available from: http://www.who.int/healthinfo/ global_burden_disease/gbd/en/. Accessed March 27, 2014.

8. Han J, Kang SH, Kim SH, et al. A framework of analysis for measuring nation's quality of life. Seoul: Korea Society of Social Studies; October 2011.

9. Ware JE Jr, Sherbourne CD. The MOS 36-item short-form health survey (SF-36): I. Conceptual framework and item selection. Med Care. 1992;30(6):473-483.

10. Ware JE Jr, Kosinski M, Bayliss MS, McHorney CA, Rogers WH, Raczek A. Comparison of methods for the scoring and statistical analysis of SF-36 health profile and summary measures: summary of results from the medical outcomes study. Med Care. 1995;33(4 Suppl): AS264-AS279.

11. Zhou J, Ru X, Hearst N. Individual and household-level predictors of health-related quality of life among middle-aged people in rural Mid-east China: a cross-sectional study. BMC Public Health. 2014;14:660.

12. Shin SG. Patterns of health-related quality of life and factors associated with health risks among Korean adults [Ph.D Dissertation]. Seoul: Seoul National University; 2010.

13. Kobau R, Sniezek J, Zack MM, Lucas RE, Burns A. Well-being assessment: An evaluation of well-being scales for public health and population estimates of well-being among U.S. adults. Health and Well Being. 2010;2(3):272-297.

14. Patrick DL, Deyo RA. Generic and disease-specific measures in assessing health status and quality of life. Med Care. 1989;27(3 Suppl): S217-S232.

15. Seong SS, Choi CB, Sung YK, et al. Health-related quality of life using EQ-5D. J Rheum Dis. 2004;11:254-262. [Korean].

16. Lee WJ, Song KH, Noh JH, Choi YJ, Jo MW. Health-related quality of life using the EuroQol 5D questionnaire in Korean patients with type 2 diabetes. J Korean Med Sci. 2012;27(3):255-260.

17. Choi YJ, Lee MS, An SY, et al. The relationship between diabetes mellitus and health-related quality of life in Korean adults: the fourth Korea national health and nutrition examination survey (2007-2009). Diabetes Metab J. 2011;35(6):587-594. 
18. Korea Center for Disease Control and Prevention (KCDC), The fourth Korea national health and nutrition examination survey (KNHANES IV) 2007-2009. Seoul: Ministry of Health and Welfare \& Korea Centers for Disease Control and Prevention. 2007.

19. Korea Center for Disease Control and Prevention (KCDC), The fifth Korea national health and nutrition examination survey (KNHANES V) 2010-2012. Seoul: Ministry of Health and Welfare \& Korea Centers for Disease Control and Prevention. 2010.

20. Rabe KF, Hurd S, Anzueto A, et al. Global strategy for the diagnosis, management, and prevention of chronic obstructive pulmonary disease: GOLD executive summary. Am J Respir Crit Care Med. 2007; 176(6):532-555.

21. Nam HS. South Korean time trade-off values for EQ-5D health states; 2010. Available from: http://www.cdc.go.kr/CDC/info/CdcKrInfo0301. jsp?menuIds=HOME001-MNU1132-MNU1138-MNU0037-MNU138 $0 \&$ cid=12449. Accessed August 4, 2015.

22. Lee YK, Nam HS, Chuang LH, et al. South Korean time trade-off values for EQ-5D health states: modeling with observed values for 101 health states. Value Health. 2009;12(8):1187-1193.

23. Lehouck A, Boonen S, Decramer M, Janssense W. COPD, bone metabolism, and osteoporosis. Chest. 2011;139(3):648-657.

24. McEvoy CE, Ensrud KE, Bender E, et al. Association between corticosteroid use and vertebral fractures in older men with chronic obstructive pulmonary disease. Am J Respir Crit Care Med. 1998;157(3 Pt 1) 704-709.
25. Di Marco F, Verga M, Reggente M, et al. Anxiety and depression in COPD patients: the roles of gender and disease severity. Respir Med. 2006; 100(10):1767-1774.

26. Brenes GA. Anxiety and chronic obstructive pulmonary disease: prevalence, impact, and treatment. Psychosom Med. 2003;65(6): 963-970.

27. Yohannes AM, Willgoss TG, Baldwin RC, Connolly MJ. Depression and anxiety in chronic heart failure and chronic obstructive pulmonary disease: prevalence, relevance, clinical implication and management principles. Int J Geriatr Psychiatry. 2010;25(12):1209-1221.

28. Anderson KL. The effect of chronic obstructive pulmonary disease on quality of life. Res Nurs Health. 1995;18(6):547-556.

29. Miravitlles M, Naberan K, Cantoni J, Azpeitia A. Socioeconomic status and health-related quality of life of patients with chronic obstructive pulmonary disease. Respiration. 2011;82(5):402-408.

30. Ringbaek T, Brøndum E, Martinez G, Lange P. EuroQoL in assessment of the effect of pulmonary rehabilitation COPD patients. Respir Med. 2008;102(11):1563-1567.

31. Pickard AS, Wilke C, Jung E, Patel S, Stavem K, Lee TA. se of a preference-based measure of health (EQ-5D) in COPD and asthma. Respir Med. 2008;102(4):519-536.

32. Rutten-van Mölken MP, Oostenbrink JB, Tashkin DP, Burkhart D, Monz BU. Does quality of life of COPD patients as measured by the generic EuroQol five-dimension questionnaire differentiate between COPD severity stages? Chest. 2006;130(4):1117-1128.
International Journal of COPD

\section{Publish your work in this journal}

The International Journal of COPD is an international, peer-reviewed journal of therapeutics and pharmacology focusing on concise rapid reporting of clinical studies and reviews in COPD. Special focus is given to the pathophysiological processes underlying the disease, intervention programs, patient focused education, and self management protocols.

\section{Dovepress}

This journal is indexed on PubMed Central, MedLine and CAS. The manuscript management system is completely online and includes a very quick and fair peer-review system, which is all easy to use. Visit http://www.dovepress.com/testimonials.php to read real quotes from published authors. 